\title{
Construção social de mercados orgânicos: o caso das Células de Consumidores Responsáveis em Florianópolis-SC
}

\author{
Organic markets social construction: the case of Responsible Consumer Cells in \\ Florianópolis-SC
}

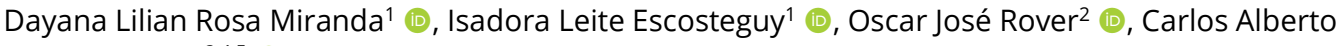
Cioce Sampaio $3,4,5$ (1)

'Laboratório de Comercialização da Agricultura Familiar (LACAF), Universidade Federal de Santa Catarina (UFSC), Florianópolis (SC), Brasil. E-mails: dayana.I.rosa@gmail.com; isaescosteguy@gmail.com

${ }^{2}$ Programa de Pós-graduação em Agroecossistemas, Laboratório de Comercialização da Agricultura Familiar (LACAF), Universidade Federal de Santa Catarina (UFSC), Florianópolis (SC), Brasil. E-mail: oscar.rover@gmail.com

${ }^{3}$ Programa de Pós-graduação em Meio Ambiente e Desenvolvimento, Universidade Federal do Paraná (UFPR), Curitiba (PR), Brasil. E-mail: carlos.cioce@gmail.com

${ }^{4}$ Programa de Pós-graduação em Desenvolvimento Regional, Universidade Regional de Blumenau - FURB, Blumenau (SC), Brasil.

${ }^{5}$ Programa de Pós-graduação em Governança e Sustentabilidade, Instituto Superior de Administração e Economia do Mercosul (ISAE), Curitiba (PR), Brasil.
\end{abstract}

Como citar: Miranda, D. L. R., Escosteguy, I. L., Rover, O. J., \& Sampaio, C. A. C. (2021). Construção social de mercados orgânicos: o caso das Células de Consumidores Responsáveis em Florianópolis-SC. Revista de Economia e Sociologia Rural, $59(2)$, e220071. https://doi.org/10.1590/1806-9479.2021.220071

\begin{abstract}
Resumo: Movimentos contemporâneos contrários às formas industriais de produção, abastecimento e consumo agroalimentar defendem processos alternativos que reconectem produtores e consumidores, resgatando valores culturais e sociais, relocalizando a agricultura nos territórios e valorizando a dimensão ambiental. Nesse contexto, destaca-se o aumento da demanda por alimentos orgânicos e mudanças nos padrões de produção e consumo, baseadas em valores de qualidade e confiança. Nessa perspectiva, este estudo objetiva analisar a experiência do Laboratório de Comercialização da Agricultura Familiar (LACAF-UFSC), com foco no projeto de extensão Células de Consumidores Responsáveis (CCR), em um esforço de compreensão da sua contribuição para a construção social de mercados de orgânicos/agroecológicos em Florianópolis-SC, Brasil. Teoricamente, o estudo define as Redes Agroalimentares Alternativas (RAA) e articula esta noção com a de Redes de Cidadania Agroalimentar (RCA). Metodologicamente, é desenvolvida uma observação participante junto à experiência do projeto supracitado, bem como a análise de dados primários e de outros documentos. Conclui-se que as CCR constituem um modelo eficaz de tecnologia social que ajuda a articular novas relações entre produção e consumo de alimentos, e se integram na lógica das RCA, representando uma forma de resistência nos mercados agroalimentares, capaz de contribuir para redesenhar cadeias de abastecimento alimentar nas grandes cidades.
\end{abstract}

Palavras-chave: redes agroalimentares alternativas, redes de cidadania agroalimentar, produtos orgânicos, agroecologia, agricultura familiar.

\begin{abstract}
Contemporary movements against industrial production forms, supply, and agrifood consumption defend alternative processes that reconnect producers and consumers, rescuing cultural and social values, relocating agriculture in the territories and valuing the environmental dimension. In this context, it is important to highlight the demand increases for organic food and changes in production and consumption patterns, based on quality and trust values. Related to this perspective, this study aims to analyze the Family Farming Commercialization Laboratory (FFCL-UFSC) experience, focusing on the extension project Responsible Consumption Cells (RCC), in an effort to comprehend its contribution to the market social construction of organics/agro-ecological in Florianópolis - SC, Brazil. Theoretically, the study defines Alternative Food Networks (AFN) and bonds its notion with Civic Food Networks (CFN). Methodologically, participant observation is developed, as well as the primary data analysis and other
\end{abstract}


documents. It was possible to conclude that the CCR is an effective model of social technology that helps articulate new production and consumption arrangements, integrating itself in the CFN logic, representing a resistance form in agrifood markets able to contribute to the food supply chains redesign in big cities.

Keywords: alternative food networks, civic food networks, organic products, agroecology, family farming.

\section{Introdução}

As estratégias de desenvolvimento operadas nas últimas décadas vêm oscilando entre dois polos divergentes. O primeiro - e predominante - é de carácter top-down, o qual define estratégias focadas no desenvolvimento de mecanismos de economia de mercado, voltadas para tornar as regiões e territórios mais competitivos, por meio da produção em grande escala. Aqui, o propósito é fortalecer a base econômica dos territórios e as transformações institucionais que ocorrem pela implantação de diversos mecanismos de indução (Gómez et al., 2015). No outro extremo, têm-se as iniciativas bottom-up ou de relações horizontalizadas, que representam a dinâmica de reestruturação econômica caracterizada por ações socialmente coletivas. Tais iniciativas têm levado a uma lógica integrada de desenvolvimento, que se aproxima do conceito de desenvolvimento à escala humana (MaxNeef, 2012), no qual se buscam satisfatores sinérgicos às necessidades sociais ${ }^{1}$. Elas trazem, portanto, uma reflexão mais profunda sobre alternativas de desenvolvimento sustentável, fomentando discussões acerca da manutenção e desenvolvimento da agricultura familiar ${ }^{2} \mathrm{e}$ de seu potencial como modelo social, econômico e produtivo, operada na lógica bottom-up de produção e consumo. Trata-se de entender em que condições os agricultores familiares, conjuntamente com os consumidores e as organizações locais envolvidas na cadeia agroalimentar, poderiam agir frente aos desafios colocados pela dinâmica atual do capitalismo na agricultura e em seus modos de produção, de forma a poder viabilizar uma relação comercial na qual os atores sociais envolvidos sejam beneficiados. Segundo Boaventura de Sousa Santos (2005), é nessa lógica bottom-up, indicada por ele como globalização alternativa, que estariam os novos caminhos da emancipação social.

Crescem esforços de pesquisas e extensão para compreender e experimentar formas alternativas de relação produção-consumo, de maneira a reivindicar qualidade e humanização no processo, bem como a necessidade de reconectar produtores e consumidores, e restabelecer sistemas agroalimentares que articulem sociedade e natureza de forma sustentável (Goodman, 2017; Renting et al., 2003; Lamine et al., 2012). Goodman (2003) associa a "virada para a qualidade" (quality turn) à proliferação de redes agroalimentares alternativas (RAA) ou Alternative Agrifood Networks (AAFN). Segundo o autor, trata-se da passagem de um 'mundo industrial', com suas convenções de qualidade padronizadas e operadas na lógica de produção em massa de mercadorias, para um ‘mundo doméstico', no qual as convenções de qualidade são pautadas na confiança, procedência, enraizamento e modos sustentáveis de produção e comercialização dos alimentos. Cassarino \& Damasceno (2013) complementam expondo que, além das imposições mercadológicas e do caráter hegemônico do processo de globalização, esse movimento baseado em "alternatividades" aponta para a construção de uma nova sociedade, mais justa, sustentável e com mais equidade social, econômica e ambiental. Para estes estudiosos, os movimentos contrários à lógica difundida pelo modelo agroalimentar industrial são notadamente capazes de construir redes de relações de produção, abastecimento e consumo alternativos.

Inserido nesta reflexão, este trabalho descreve e analisa a experiência do Laboratório de Comercialização da Agricultura Familiar (LACAF-UFSC) no desenvolvimento de uma tecnologia

\footnotetext{
'Satisfatores sinérgicos são aqueles que satisfazem uma dada necessidade ao mesmo tempo em que estimulam e contribuem para a realização de outras, a exemplo da amamentação, que satisfaz a necessidade de subsistência e, concomitantemente, satisfaz as necessidades de proteção, afeto e identidade (Max-Neef, 2012).

2Para além dos impactos ambientais positivos da agricultura de pequena escala, a agricultura familiar ocupa um espaço importante na agenda de desenvolvimento sustentável do País, seja pela contribuição econômica que pode dar, seja em virtude dos aspectos distributivos e de equidade que estão associados à atividade (Buainain, 2006).
} 
social ${ }^{3}$ chamada de Células de Consumidores Responsáveis (CCR), objetivando compreender a contribuição da iniciativa para a construção social de mercados para alimentos orgânicos/agroecológicos ${ }^{4}$, em Florianópolis-SC, Brasil. As CCR consistem em arranjos inovadores de venda direta por pedido e pagamento antecipado de alimentos orgânicos/agroecológicos, a preços abaixo do praticado no mercado local. O modelo é estruturado a partir de "cestas fechadas" entregues semanalmente em pontos de entrega espalhados por zonas/bairros da cidade de Florianópolis.

A presente pesquisa justifica-se na premissa de que a construção social de mercados agroalimentares tem sido considerada na literatura acadêmica como uma nova modalidade de organização para o desenvolvimento de territórios locais/regionais, alicerçada em uma maior aproximação entre produtores, geralmente rurais, e consumidores, normalmente urbanos, e a consequente construção social da qualidade dos alimentos (Marsden et al., 2000).

Destarte, o presente artigo visa contribuir para os estudos ligados ao desenvolvimento sustentável das cidades e regiões periurbanas, e aos modelos alternativos de desenvolvimento. O texto está organizado, além desta introdução, em cinco partes, a saber: (i) marco teórico conceitual; (ii) descrição da experiência das Células de Consumidores Responsáveis - CCR; (iii) metodologia; (iv) resultados e discussões, e, por fim, (v) conclusões.

\section{Fundamentação teórica}

Os processos de transformação sob os quais passaram as formas de produção, abastecimento e consumo alimentar, desde os tempos da chamada "Modernização Conservadora" $^{5}$ até a atualidade, produziram um distanciamento entre produtores e consumidores, refletindo na perda de conhecimentos tradicionais, na desvinculação de valores e significados culturais atribuídos aos alimentos, e na desestruturação dos mercados e produções de variedades de alimentos locais (Marsden et al., 2000). Tal modernização produziu efeitos deletérios, cujos resultados podemos constatar não somente através da desconexão entre quem produz e quem consome, mas também pela massiva industrialização do campo, pela transformação dos alimentos em simples mercadorias e pela implantação de um modelo de agricultura industrial de alta produtividade, que gerou situações críticas a muitos agricultores familiares. Dentre estas, podemos destacar o endividamento, a queda de preços dos produtos e a transferência da renda agrícola para as indústrias de insumos e processamento de alimentos (Marsden et al., 2000).

Como uma contraposição à hegemonia desse modelo, surgiram movimentos sociais contrários às formas industriais de produção agroalimentar, buscando direcionar os processos de plantio, abastecimento e consumo de alimentos rumo a caminhos alternativos. Autores, como Goodman (2017), Renting et al. (2003) e Lamine et al. (2012), analisam o crescimento de tais movimentos. Muitos destes movimentos defendem modos sustentáveis de agricultura, reconectando produtores e consumidores, resgatando valores culturais e sociais tradicionais, relocalizando a produção dos alimentos nos territórios e promovendo relações mercantis de proximidade.

\footnotetext{
${ }^{3}$ Tecnologia Social (TS) engloba iniciativas relacionadas ao trânsito da economia informal para a Economia Solidária (ES) e seus empreendimentos (Dagnino, 2014).

${ }^{4} \mathrm{Na}$ experiência, é definido que se busca a construção deste tipo de mercado, fazendo referência a alimentos orgânicos/agroecológicos. Destaque-se que os alimentos comercializados são na maioria orgânicos certificados pela Rede Ecovida de Agroecologia. Entretanto, também são ofertados alguns alimentos não certificados e que estão em conversão orgânica, ou são produzidos com métodos que reduzem o uso de insumos agroquímicos. A este conjunto, a experiência denomina de alimentos orgânicos/agroecológicos.

${ }^{5} \mathrm{~A}$ alteração da base técnica da agricultura, associada à sua articulação "[...] com a indústria produtora de insumos e bens de capital para a atividade, juntamente com a indústria processadora de produtos naturais", levou à formação do chamado "complexo agroindustrial" (Delgado, 1985, p. 19) ou à "industrialização da agricultura" (Silva, 2003, p. 19). Essa modernização fora feita sem que a estrutura da propriedade rural fosse alterada, tornando-se maiores as disparidades de renda, acentuando o êxodo rural, aumentando a taxa de exploração da força de trabalho nas atividades agrícolas e a autoexploração nas propriedades menores, endividando o pequeno agricultor. Enfim, em termos gerais, piorando a qualidade de vida da população trabalhadora do campo. Por isso, a expressão "modernização conservadora".
} 
Os mercados sempre foram socialmente construídos (Granovetter, 1985; Polanyi, 2000). Sob a ótica de Polanyi (2000), através da organização contra-hegemônica articulada em diversos níveis (social, político e econômico) e escalas (do local ao global), assim como da ativação e enraizamento de instituições democráticas, os atores sociais podem estabelecer mecanismos de regulação e controle do mercado. Tal controle social pode ser para prevenção ao risco da exacerbação (ideologia neoliberal) e do autoritarismo do Estado, sendo capaz de promover processos de mudança social, democratização econômica e transformação estrutural das sociedades.

Nesse sentido, a abordagem da construção social dos mercados ligada às RAA entende que estes são espaços de interação social e não apenas o encontro entre oferta e demanda, nos quais se manifestam diferentes interesses e se articulam as mais distintas arenas sociais (Granovetter, 1985; Marques, 2003; Steiner, 2006; Schneider et al., 2016). A articulação entre produção, abastecimento e consumo, através do estabelecimento de relações sociais em redes, está entre os pontos centrais analisados no presente trabalho. Tais redes integram produtores, consumidores, organizações sociais e comerciais, e instituições.

As novas propostas de desenvolvimento rural que fazem crítica às cadeias agroalimentares industriais são sumarizadas nas noções e experiências denominadas Cadeias Agroalimentares Curtas (Short Food Supply Chain - SFSC) e nas Redes Agroalimentares Alternativas (Alternative Agrifood Networks - AAFN). Essas cadeias priorizam aspectos ligados ao enraizamento, relocalização e inclusão de atributos de qualidade vinculados a aspectos culturais (tradições e modo de vida, por exemplo) e ambientais, além da valorização das pessoas envolvidas e de seu "saber fazer". Goodman (2003) destaca que se trata de um modelo que se opõe aos impactos ambientais e ao desenraizamento promovido pelas cadeias industriais e suas dinâmicas de produção, abastecimento e consumo de alimentos. Vale ressaltar que tais iniciativas são importantes no mercado alimentar do continente europeu, no qual mudanças estruturais se deram principalmente pela demanda dos consumidores quanto a procedência e qualidade dos alimentos (Kneafsey et al., 2013), acarretando uma maior apropriação do valor do trabalho por parte dos agricultores e dinâmicas organizativas envolvidas, trilhando assim novas alternativas de mercado (Marsden et al., 2000; Ploeg, 2011 apud Tregear, 2011).

Ao tratar de alternatividades ao modelo agroalimentar industrial e ao contexto alimentar sob o qual a sociedade contemporânea encontra-se atualmente, considera-se que a criação de iniciativas que venham a conectar-se entre si, atuando sob forma de rede horizontalizada, consiste em desenvolver mecanismos de emancipação social diante de um sistema agroalimentar que impõe lógicas de abastecimento e consumo nas cidades contemporâneas. Conforme descrito por Darolt et al. (2016), rede agroalimentar alternativa é um termo recorrentemente utilizado na literatura internacional, que designa uma categoria genérica de análise acadêmica para o estudo de alternatividades às formas dominantes do atual modelo agroalimentar. Os autores afirmam que as estratégias das RAA são pautadas na cooperação social e em parcerias entre produtores e consumidores, na reconexão entre produção e consumo dentro de padrões sustentáveis, na dinamização de mercados locais com identidade territorial, na revalorização da circulação de produtos de qualidade diferenciada e na relação de confiança estabelecida entre as partes.

Dada a abrangência da terminologia referente às redes agroalimentares alternativas, intrínsecos a elas aparecem os circuitos curtos de comercialização ${ }^{6}$ (CCC), que são formas de comercialização que indicam a aproximação entre agricultores e consumidores (Santos, 2003). Tal terminologia consiste basicamente na mesma definição teórica que trata das "Cadeias Agroalimentares Curtas" ou Short Food Supply Chains, anteriormente citadas.

Segundo Schneider (2010, p. 526):

O desafio para a agricultura familiar consistiria na melhoria de sua capacidade de interação social e inserção em mercados locais ou non-standards (...). Neste cenário, os

${ }^{6}$ Darolt et al. (2016) chamam a atenção para definições mais pragmáticas de circuito curto (CC), caracterizando os circuitos de distribuição que mobilizam até - no máximo - um intermediário entre produtor e consumidor, sendo a venda direta e a venda indireta via um único intermediário. 
agricultores familiares precisariam desenvolver habilidades para construir os novos mercados, saber "ler as tendências e os gostos dos consumidores", serem capazes de organizar redes sócio-técnicas (de tipo fair trade ou solidárias) e cadeias curtas de produção e comercialização (short food supply chains) que permitam atender a demanda.

Nesse sentido, Marsden et al. (2000) relacionam as cadeias curtas de abastecimento agroalimentar a novas formas de produção e relacionamento entre agricultores e consumidores. Tal abordagem propõe a aproximação das formas de produção e comercialização relacionadas à proximidade entre produtores primários e destinatários finais. Esta se traduz em uma forma de contraposição aos circuitos longos das cadeias industriais de abastecimento de alimentos. Define-se como "cadeias curtas de abastecimento alimentar" aquelas que reivindicam uma reaproximação entre produtores e consumidores, como sendo fatores essenciais para a consolidação de práticas e processos de desenvolvimento rural (Marsden et al., 2000). Os autores indicam que, nas cadeias curtas, o conjunto de atores sociais está diretamente envolvido na produção, no processamento, na distribuição e no consumo dos produtos alimentares, bem como nas relações estabelecidas entre produtores e consumidores, e nas informações acerca do produto que está sendo comercializado, relativas ao lugar e ao espaço de produção (origem; território), aos valores sociais das pessoas envolvidas no processo e aos métodos de produção utilizados.

O que Marsden et al. (2000) denominam de cadeia curta se insere no enfoque das RAA, direcionado à evidenciação do seu potencial alternativo às cadeias industriais, levando em consideração também as questões políticas do consumo (Schneider \& Gazolla, 2011). Essas novas estruturas estariam relacionadas a um novo paradigma de desenvolvimento rural, enraizado na cultura, na história e nos ecossistemas locais (Ploeg, 2006). Por sua vez, estas se propõem a promover (i) a valorização de produtos alimentares de acordo com critérios de qualidade vinculados ao sabor, ao aroma e a textura; (ii) a construção de relações de confiança entre produtores e consumidores; (iii) o conhecimento por parte de quem consome sobre o local e as técnicas de produção utilizadas, e as questões socioeconômicas e ambientais relativas aos agentes envolvidos, etc. Ademais, estas cadeias agrícolas heterogêneas e regionalizadas possibilitariam a valorização da identidade cultural de uma região, enaltecendo o respeito da produção dos alimentos para com os recursos naturais e com o conhecimento tácito local (Ploeg, 2011 apud Tregear, 2011).

Análises mais recentes de distintas naturezas organizacionais denotam a importância de outras dimensões que qualificam e corroboram a unificação dos critérios estruturantes que definem essas redes e cadeias. Essas abordagens optam por caracterizar tais estruturas como redes de cidadania agroalimentar (RCA) ou civic food networks (CFN) (Goodman \& Sage, 2014), levando em consideração a justiça e soberania alimentar, e a relação entre as políticas públicas e as organizações da sociedade civil, dando destaque ao tema da governança alimentar. Evidencia-se que as autodenominadas RAA são muitas vezes integradas sistemicamente àquilo que se propõem alternativas e que, portanto, faria mais sentido falar numa cidadania se organizando para governança do acesso a uma alimentação de qualidade (Renting et al., 2012). A promoção e integração de redes de cidadania agroalimentar- (Renting et al., 2003, 2012; Lamine et al., 2012), no sentido da promoção do acesso ao alimento orgânico/agroecológico, da sensibilização para o consumo e da dinamização de formas de consumo responsável, assim como da organização e planejamento da produção - reforçam abordagens que visam à promoção de maior democracia alimentar (Renting et al., 2012; Lamine et al., 2012)7. Desta forma, valores, como solidariedade, reciprocidade e cidadania, aparecem como fundamentais para o estabelecimento destas redes. $A$ relação com políticas públicas e organizações da sociedade civil (além de questões, como proximidades geográficas e relacionais entre produção e consumo) está estritamente correlacionada aos critérios estruturantes de uma RCA (Goodman \& Sage, 2014; Renting et al., 2003, 2012; Lamine et al., 2012).

\footnotetext{
${ }^{7}$ Cabe ressaltar que tal dinâmica aproxima-se do movimento em torno da Ecogastronomia, a qual questiona a sustentabilidade dos sistemas globais de alimentos e bebidas, ressaltando os problemas econômicos, socioculturais e ambientais desses sistemas. Segundo Bucak \& Demir (2014), a Ecogastronomia pode ser definida como um processo associado a agricultura e produção de alimentos, venda e consumo, o qual inclui os elementos sociais, psicológicos, culturais e políticos presentes ao longo da cadeia, indo ao encontro de modelos que defendem um processo de engajamento coletivo em prol da superação das contradições que envolvem o sistema agroalimentar industrial.
} 


\section{Metodologia}

Os métodos utilizados no presente trabalho constituíram-se em: (a) revisão bibliográfica em torno da temática que trata das redes agroalimentares alternativas e redes de cidadania agroalimentar, promovendo interfaces com a reflexão sobre cadeias curtas de abastecimento alimentar/circuitos curtos de comercialização; (b) análise de dados primários coletados com consumidores através de questionários, além de outros documentos disponíveis no LACAF, como atas de reuniões e encaminhamentos realizados; (c) entrevistas realizadas com agricultores ligados às CCR; (d) análise de materiais audiovisuais produzidos (vídeos), e (e) observação participante do projeto das CCR, junto a consumidores e agricultores.

Destaca-se que, das 10 CCR existentes, se fez um recorte e analisou-se uma CCR isoladamente, sendo a CCR-UFSC Trindade, que conta com o maior número de consumidores, sendo também a primeira a ser criada via modelo de venda direta por pedido antecipado (VDPA).

Os questionários com consumidores foram aplicados online e os dados obtidos foram coletados e tabulados entre os meses de fevereiro e julho de 2018. Foram enviados aos 99 consumidores/as da CCR-UFSC Trindade, obtendo-se, finalmente, 23 respostas relacionadas ao perfil socioeconômico dos consumidores e 39 respostas acerca da pesquisa sobre a motivação de participação no projeto. Foram analisadas ainda atas das reuniões realizadas com a presença de agricultores e consumidores, assim como anotações e diários de campo da observação participante.

\section{A experiência das Células de Consumidores Responsáveis - CCR}

O Projeto de Extensão intitulado "Abastecimento de alimentos agroecológicos em cidades populosas: uma tecnologia social de venda direta com educação alimentar" é financiado pelo Conselho Nacional de Desenvolvimento Científico e Tecnológico - CNPq e prevê a criação de Células de Consumidores Responsáveis (CCR), objetivando fortalecer redes agroecológicas de abastecimento alimentar na Grande Florianópolis. Assim, através da venda direta de alimentos orgânicos/agroecológicos, da educação para o mercado ${ }^{8}$ e do consumo ético/responsável, visa-se consolidar o modelo como uma iniciativa de circuito curto de comercialização de alimentos bons, limpos e justos.

O projeto surgiu da necessidade de grupos de agricultores familiares viabilizarem mercados mais justos e rentáveis para seus produtos - ao mesmo tempo em que crescia a demanda por alimentos mais saudáveis e orgânicos em Florianópolis-SC -, além de buscar a ampliação do acesso a estes alimentos.

Foram criadas Células que consistem em arranjos inovadores de venda direta por pedido antecipado de alimentos orgânicos/agroecológicos. Neste modelo, os pagamentos são realizados mensalmente e de forma antecipada, via internet. Os produtos são fornecidos em um modelo de "cesta fechada", ou seja, os(as) consumidores(as) não escolhem previamente quais alimentos irão receber, pois estes são entregues de acordo com as variedades disponíveis na época/estação. Assim, respeita-se a sazonalidade da produção dos agricultores, havendo um acordo estabelecido que garante aos consumidores tipos e diversidades mínimas de produtos (folhosas, tubérculos, raízes e frutas), peso aproximado por tamanho de cesta e preços fixos. A entrega dos alimentos ocorre semanalmente em pontos de entrega comum a um conjunto de consumidores(as) de cada CCR, como: escolas, ambientes de trabalho, universidades, empresas, residências. Deste modo, o arranjo das CCR estabelece um modelo de venda garantida aos(às) agricultores(as), bem como diminui os

${ }^{8}$ Entende-se por educação para o consumo e consumo ético e responsável, o desenvolvimento de padrões e níveis de consumo mais sustentáveis, que envolve a construção de relações de proximidade, confiança e corresponsabilidade de produção entre agricultores e consumidores. O apoio a formas alternativas de produção conta, portanto, com uma ampla identificação e participação dos consumidores, articulando experiências bem-sucedidas em "mercados bons, limpos e justos", representando, desta forma, mecanismos de resistência, reorientação dos modelos produtivos e tentativas de interferência nas agendas hegemônicas. Assim, criam-se redes de intercâmbio de informação e de aprendizagem do exercício da cidadania, promovendo, para além de inovações tecnológicas, mudanças nas escolhas individuais de consumo e ações coletivas, que por sua vez, acarretam mudanças políticas, econômicas e institucionais, fazendo com que os padrões e os níveis de consumo se tornem mais localizados e sustentáveis. 
custos de logística. Além disto, é viabilizado o acesso com fácil retirada dos alimentos para os consumidores, a preços abaixo do praticado no mercado local.

Os atores envolvidos na produção e no consumo assumem nesta articulação uma série de responsabilidades compartilhadas. Estas são estabelecidas e acordadas coletivamente (em reuniões), as quais organizam a dinâmica de compra e venda, bem como promovem a relação direta entre produtor e consumidor. Nesse sentido, ressalta-se o potencial para a construção de vínculos de proximidade entre quem produz e quem consome.

Inspirado em experiências já consolidadas na Itália (Gruppi di Acquisto Solidale-GAS ${ }^{9}$ ) e conhecedor de outros modelos, como o das AMAP francesas e das CSA ${ }^{10}$, o projeto objetiva contribuir para a construção de uma Rede de Cidadania Agroalimentar na Região da Grande Florianópolis, gerando dinâmicas de mercado e consumo ético/responsável, ampliando o abastecimento de produtos orgânicos/agroecológicos provenientes da agricultura familiar e despertando no consumidor a importância do seu papel como coprodutor ${ }^{11}$ na cadeia de alimentos.

Desta forma, o projeto busca a criação de novos arranjos entre produção e consumo, nos quais a feira deixa de ser o único formato de venda direta. Assim, se estabelecem outros modelos de comercialização, os quais buscam aproximar agricultores e consumidores, e promover o acesso a mercados alternativos. Nesse sentido, supre-se a crescente demanda por alimentos orgânicos certificados, a preços acessíveis a diversas camadas socioeconômicas.

A proposta das CCR iniciou-se em 2016 e estruturou-se em duas fases: a primeira, iniciada em novembro de 2016, contou com a criação de três CCR em modelo de cesta "aberta"12 (Associação Comunitária do Bairro Sambaqui, Escola SOCIESC, Agência da Caixa Econômica Federal da Beira Mar de Florianópolis ${ }^{13}$ ). A gestão organizacional era realizada por meio do envio de uma lista com os produtos ofertados via e-mail em planilha Excel®. Porém, este modelo mostrou-se deficitário, ocorrendo a fragilização e consequente desativação das experiências iniciais. As dificuldades centrais enfrentadas foram: (i) a operacionalização dos pedidos (planilhas, excesso de recebimento de e-mails, etc.); (ii) o reduzido período de 30 minutos, disponibilizado aos consumidores, para a retirada dos produtos nos pontos de entrega, e (iii) os ainda altos preços praticados, fazendo com que os consumidores preferissem ir às feiras em vez de comprá-los sem vê-los, ao escolhê-los. Entretanto, estas experiências possibilitaram a observação das limitações e a construção de aprendizados sobre os futuros arranjos a serem criados e adaptados.

Na segunda fase, o projeto experimentou um arranjo distinto, que opera através de: (i) dois modelos de cestas fechadas, pequena e grande, com diversidade que varia de nove a 13 itens, com aproximadamente $4,5 \mathrm{~kg}$ e $9 \mathrm{~kg}$ cada cesta, respectivamente. Os preços são fixos, sendo 29 reais a cesta pequena e 53 reais a cesta grande. O pagamento é antecipado e mensal, contando com comunicação via internet; (ii) responsabilidades compartilhadas entre agricultores e consumidores; (iii) reuniões de construção e avaliação, e (iv) processos autogestionários de cada CCR.

Em novembro de 2017, foi criada a primeira Célula neste novo modelo, tendo um ponto de partilha estruturado na Universidade Federal de Santa Catarina, no campus da UFSC Trindade. É importante ressaltar que este artigo trata de analisar em profundidade o caso desta CCR.

\footnotetext{
${ }^{9}$ De forma objetiva, um GAS pode ser entendido como um grupo de compras, sobretudo de produtos agroalimentares (frutas, legumes, derivados lácteos etc.), organizado normalmente por consumidores e identificado com a abordagem política do ato de consumo (Anjos \& Caldas, 2018).

${ }^{10}$ Comunidades que Sustentam a Agricultura (CSA) e esquemas semelhantes conhecidos por diferentes nomes em outros Estados-Membros da União Europeia (Association pour le Maintien d'ne Agriculture Paysanne - AMAP, etc.) baseiam-se na parceria de longo prazo entre um ou vários produtores e seus consumidores, na qual é firmada uma associação, em maior ou menor medida, envolvendo decisões coletivas relativas ao trabalho e à produção (Kneafsey et al., 2013).

${ }^{11}$ Coprodução, de acordo com o movimento Slow Food, é a conscientização do ato do consumo, ou seja, a responsabilização do consumidor pelo ciclo produtivo do alimento, dado que o coprodutor orienta o mercado e a produção por meio de suas escolhas, assumindo um novo papel no processo quando se torna consciente de seus atos (Petrini, 2009).

${ }^{12}$ Consumidores(as) escolhem quais produtos comprar a partir de uma lista enviada previamente pelos agricultores. ${ }^{13}$ Estas CCR eram atendidas por um grupo de sete famílias agricultoras de Biguaçu-SC da Rede Ecovida de Agroecologia.
} 
Em outubro de 2019,encontravam-se em operação dez CCR com quase 400 famílias de consumidores, abastecidas por quatro grupos de agricultores vinculados à Rede Ecovida de Agroecologia. As CCR são: CCR UFSC Trindade, no bairro Trindade; CCR Escola da Fazenda (EFaz), no bairro Campeche; CCR Estreito, no continente de Florianópolis, bairro Estreito; CCR da Escola Sociesc, no bairro Itacorubi; CCR CCA/UFSC, no campus das Ciências Agrárias da UFSC, também no bairro Itacorubi; CCR FETAESC ${ }^{14}$, no bairro Barreiros, em São José-SC; CCR CRAS ${ }^{15}$, no continente de Florianópolis, bairro Capoeiras; CCR do Centro de Saúde (CCR Saúde); CCR Lagoa, no bairro Lagoa da Conceição; CCR Centro Co-working, que funciona dentro de um co-working no bairro Prainha. Até o presente momento, totalizam-se então 10 Células de Consumidores Responsáveis em pleno funcionamento. Cada grupo de agricultores que abastece as CCR possui entre duas e três CCR para abastecer. Os grupos de agricultores são: Grupo de Agricultores Agrodea, composto por 14 famílias da região do Alto Vale do Itajaí - SC, situadas nos municípios de Imbuia, Vidal Ramos e Leoberto LealSC; Grupo de agricultores Flor do Fruto, composto por 12 famílias do município de Biguaçu-SC; Grupo APAOC, composto por 10 famílias de agricultores situadas no município de Chapadão do Lageado-SC; Grupo de Agricultores Associada, que conta com 12 famílias agricultoras situadas nos municípios de Major Gercino, Nova Trento, Angelina e Leoberto Leal-SC.

Das aproximadamente 400 cestas comercializadas, estima-se que, no mínimo, o dobro de consumidores é beneficiado pelas CCR de forma direta, dado que as cestas são consumidas em sua maioria por famílias ou grupos de pessoas, e não individualmente.

O modelo das CCR está sendo replicado por outros grupos de produtores e consumidores em Florianópolis e região, que adotam os mesmos princípios de funcionamento quanto à venda direta por pedido antecipado (VDPA) e outras especificações, mas variam com outras inovações.

O arranjo organizacional envolvendo universidade, escolas, grupos de consumidores, grupos de agricultores e organizações de apoio vem fortalecendo uma rede de Cidadania agroalimentar na RMF, que, para além da compra e venda de alimentos, se articula em atividades de formação, no mapeamento das experiências de venda direta na Grande Florianópolis, na proposição de legislações de apoio à agroecologia e de restrição ao uso de agrotóxicos, dentre outras. A experiência articula mobilização social e integração de atores socioeconômicos até então distantes, fomentando a organização de uma rede em torno dos alimentos orgânicos/ agroecológicos e da construção social de mercados.

\section{Resultados e discussões}

A organização de alternativas de produção e consumo de alimentos constitui-se em processo sociológico extremamente complexo e diversificado, seja do ponto de vista das características de origem, funcionamento e gestão desses mercados, ou em relação aos valores sociais e culturais mobilizados pelos atores para consolidar formas diferenciadas de produzir e consumir. Tendo em vista a centralidade do consumo na contemporaneidade, as práticas que o envolvem influenciam as relações e os modos de socialização humana (Bauman, 2008).

Para compreender as análises sobre construção social de mercados que se farão neste trabalho, necessário se faz tratar das especificidades contidas no modelo das CCR.

O esforço dos agricultores para preparar as cestas de alimentos - e a confiança dos consumidores, que consentem em receber produtos semanais sem saber ao certo quais serão, conhecendo apenas a origem e procedência do alimento - evidencia que a construção desta tecnologia social tem reconfigurado os modos de socialização de seus integrantes. Demonstra-se, a partir desta e de outras ações, uma sensibilização para a dinamização de formas de consumo responsável através de, para além da promoção do acesso ao alimento orgânico/agroecológico, estímulo e suporte de práticas de consumo consciente/responsável, como evidenciado por Renting et al. (2012); Lamine et al. (2012), ao tratarem dos elementos relativos à democracia agroalimentar presente nas RCA.

A partir dos questionários enviados aos(às) consumidores(as), constatou-se que $24 \%$ dos entrevistados haviam iniciado o consumo de alimentos orgânicos no período de um a seis

\footnotetext{
${ }^{14}$ Federação dos trabalhadores na agricultura de Santa Catarina.

${ }^{15}$ Centro de Referência em Assistência Social de Florianópolis-SC.
} 
meses, tempo que correspondia à existência da CCRUFSC. Nesse cenário, a implementação da tecnologia social, ao aproximar o alimento do local de trabalho e da moradia das pessoas, promoveu um aumento da adesão de consumidores desses alimentos (Figura 1).
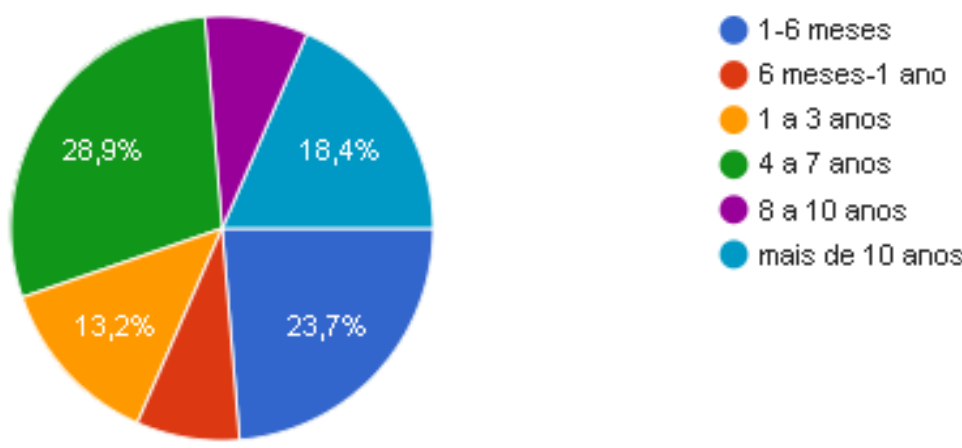

Figura 1 - Período de tempo que os consumidores da CCRUFSC Trindade consomem alimentos orgânicos/agroecológicos. Fonte: Os autores, 2018.

O crescimento da CCR UFSC Trindade se confirma quando se observa o número de cestas, que variou inicialmente de 27 para 143 cestas, no período de um ano (de 23 de novembro de 2017 a 22 de novembro de 2018). O crescente interesse de novos consumidores em integrar o projeto gerou uma lista de espera de aproximadamente 15 pessoas, devido à incapacidade do grupo de agricultores em atender toda a procura. Desta forma, as famílias agricultoras organizam sua produção para que haja um equilíbrio entre oferta e demanda.

Compreendendo as três CCR abastecidas pelo grupo AGRODEA (UFSC Trindade, Estreito e EFaz), observa-se um aumento do valor total arrecadado pelas famílias agricultoras ao longo do ano, o que representa, segundo os agricultores, um ótimo incremento de renda para os núcleos familiares (Figura 2).

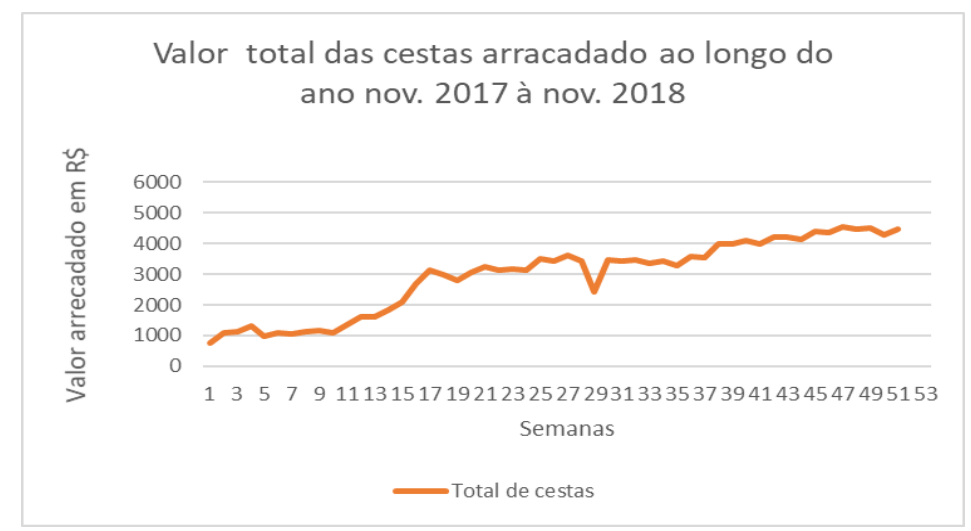

Figura 2 - Valor das cestas em reais arrecadado pelo grupo de agricultores ao longo do ano (23 nov. de 2017 a 24 de nov. de 2018). Fonte: Os autores, 2018.

Segundo depoimento de um produtor que entrega para as cestas: "o projeto tem ajudado bastante na produção e geração de renda, e estimulado muito o pessoal. Como a venda é certa, a gente planta sem medo de não vender, como no caso da feira" (Entrevistado 11).

Ainda observando a Figura 2, nota-se uma queda de receita na semana de número 29, dado o período de férias escolares, fato que não representou grandes perdas na renda das famílias ao longo do período.

Para além da geração de renda para os agricultores, podem-se observar os benefícios econômicos também para os consumidores das CCR, num comparativo de preços entre o 
modelo das CCR e demais canais de comercialização (feiras, lojas especializadas, redes de supermercados). Segundo o Boletim de Preços de Alimentos Orgânicos no Varejo de Florianópolis (Grade \& Mergen, 2018), observa-se uma diferença significativa nos valores por quilograma destes alimentos. Este documento foi elaborado a partir de um levantamento de preços de alimentos orgânicos que comporiam uma "cesta básica" orgânica. A cesta sugerida tem 8,4 kg família/mês e é composta por: 2,4 kg de raízes, tubérculos e bulbos; $1 \mathrm{~kg}$ de frutos hortícolas; $3 \mathrm{~kg}$ de folhosas e hortaliças flores, e $2 \mathrm{~kg}$ de frutas (Grade \& Mergen, 2018). Nas feiras diretas, o preço médio operado por quilograma do orgânico, nos meses de junho, julho, agosto e setembro de 2018 , foi de $R \$ 9,67 / \mathrm{kg}$, seguido de $R \$ 12,82 / \mathrm{kg}$ nas lojas especializadas e $R \$ 23,00 / \mathrm{kg}$ nos supermercados. Já as CCR trabalham com um preço médio de $R \$ 5,80 / \mathrm{kg}$.

Se os preços médios apresentados acima forem transformados para uma cesta orgânica de 8,4 kg, tem-se os valores a seguir: (i) feiras $R \$ 81,28 / \mathrm{kg}$; (ii) lojas especializadas $R \$ 107,68 / \mathrm{kg}$, e (iii) supermercados $R \$ 196,20 / \mathrm{kg}$, numa cesta orgânica. É importante constatar que se fosse aplicado o preço médio de $\mathrm{R} \$ 5,8 / \mathrm{kg}$ da cesta da CCR aos $8,4 \mathrm{~kg}$ da cesta sugerida, a mesma custaria $R \$ 48,72$, ou seja, uma economia de até $R \$ 147,32$, quando comparado ao preço dos mesmos alimentos adquiridos em um supermercado (Figura 3). Destaca-se, ainda, que as CCR trabalham com preços fixos, o que corresponde a uma estabilidade dos mesmos ao longo dos meses, sendo que, nos demais equipamentos comerciais, os preços variam conforme a disponibilidade de cada produto em específico.

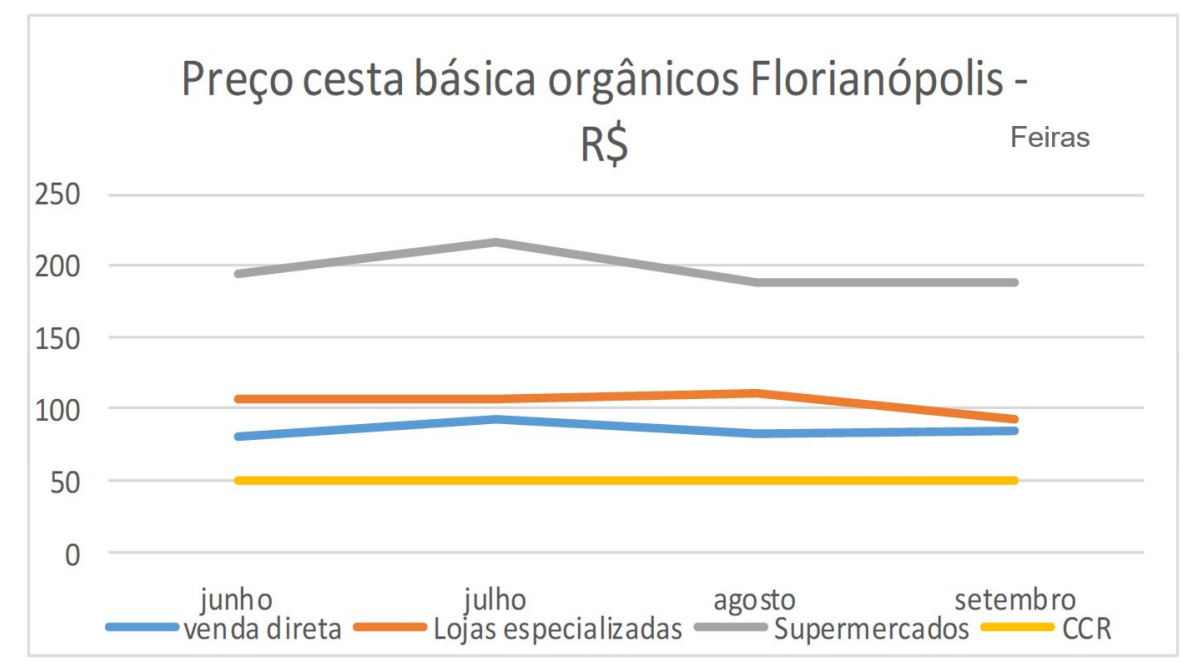

Figura 3 - Preço da cesta básica de orgânicos em Florianópolis, de junho a setembro de 2018, em reais. Fonte: Grade \& Mergen (2018), adaptado pelos autores, 2018.

No modelo das CCR, as cestas correspondem semanalmente a pesos aproximados de $4,5 \mathrm{~kg}$ a $9 \mathrm{~kg}$ (dependendo do modelo escolhido), trazendo maior diversidade de produtos (itens), quando comparadas à cesta básica sugerida pelo Boletim analisado acima. Diante do exposto, é possível verificar que o modelo das CCR promove o acesso barateado de orgânicos para os consumidores que desejam consumir tais produtos, promovendo dessa forma uma democratização agroalimentar em Florianópolis-SC. Conforme exposto por Renting et al. (2012) e Lamine et al. (2012), este tipo de inciativa integra as chamadas redes de cidadania agroalimentar, contribuindo para a construção social de mercados de orgânicos/agroecológicos na cidade.

A iniciativa das CCR representa a criação de um canal de comercialização direta por meio da articulação de atores sociais que compartilham visões comuns de desenvolvimento, ao passo que buscam fortalecer as economias locais articulando mercados de proximidade. Pautados em princípios de consciência, confiança e reciprocidade, iniciativas como esta agem como "engrenagens" para novas relações econômicas, gerando dinâmicas de mercado e consumo ético/responsável, e representando, portanto, uma forma de construção social de mercados através da formação de redes de produção-consumo.

Outro aspecto importante é a mudança de hábitos de consumo, com as CCR representando uma forma eficaz de negação da padronização agroalimentar imposta pelo 
sistema industrial. A grande maioria dos consumidores (34 dos 39 respondentes) afirmou que, após aderirem à CCR UFSC Trindade, modificaram seus hábitos alimentares (Figura 4). Tal afirmativa esteve sempre presente nas falas dos consumidores nas reuniões mensais de autogestão das CCR, bem como em entrevistas dadas nos vídeos feitos ao longo do Projeto ${ }^{16}$. Cabe reforçar que nas cestas semanais vêm os produtos da época, disponíveis nas unidades de produção conforme a sazonalidade agroecológica.

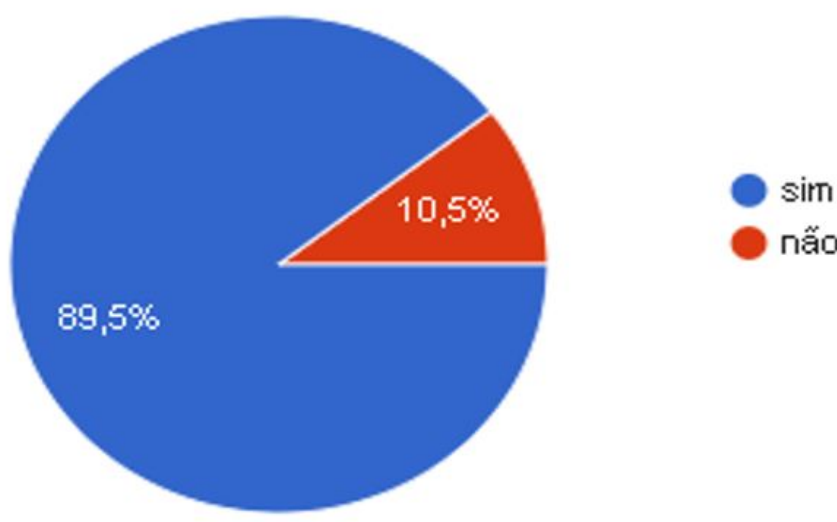

Figura 4 - Mudança de hábitos alimentares das famílias consumidoras após aderirem à CCR. Fonte: Os autores, 2018.

Dados os fatores 'proximidade' e 'redução da intermediação', atuando estes como uma ferramenta de desenvolvimento econômico e social do território e influenciando de forma positiva nos hábitos alimentares saudáveis, a comunidade passa a ter acesso a um produto de qualidade, a preço reduzido e direto do produtor, características de um circuito curto de comercialização, com elementos de uma rede de cidadania agroalimentar. Além do acesso facilitado ao mercado de orgânicos para os consumidores e da maior rentabilidade para os agricultores, as CCR possibilitam o fortalecimento e a estruturação da agricultura regional de base agroecológica.

É importante ressaltar também a relação de confiança e proximidade que o novo modelo gera entre produtores e consumidores, dada à transparência na cadeia alimentar e ao conhecimento por parte dos consumidores sobre a origem e procedência dos alimentos, tal como proposto por Marsden et al. (2000), ao tratarem da reaproximação entre produtores e consumidores através das cadeias curtas de abastecimento alimentar, como um fator essencial ao processo de desenvolvimento rural. Este foi um dos principais determinantes no desenvolvimento da governança da rede e da autogestão das Células, não sendo o mercado definido apenas pelos critérios mercantis, mas pelo conjunto de fatores citados acima. Destaca-se que a governança, quando cidadãos assumem para si responsabilidades na gestão das cadeias agroalimentares, aparece intrinsecamente ligada à noção de uma RCA, que, para além da organização espontânea e do relacionamento baseado na confiança e proximidade, mostra-se plenamente identificada com a democratização ${ }^{17}$ do acesso e consumo do alimento orgânico/agroecológico.

Nesse sentido, nota-se que o modelo adotado pelas CCR traduz uma experiência empírica de RCA, que qualifica e corrobora a unificação de critérios estruturantes descritos no marco teórico, tais como: o acesso ao alimento orgânico/agroecológico; a promoção de formas de consumo responsáveis; a organização e o planejamento da produção no campo; a democracia, justiça e soberania alimentar; a exaltação de valores ligados a solidariedade, reciprocidade e cooperação; a autogestão, entre outros.

\footnotetext{
${ }^{16}$ Reportagem RIC TV - SC (RIC Mais, 2019), Reportagem Cozinha a dois (YouTube, 2019), Reportagem TV UFSC (Facebook, 2019). ${ }^{17}$ Segundo o Dicionário Aurélio (Holanda, 2010) da Língua Portuguesa, "democratização" significa: ação de democratizar, tornar democrático, segundo os preceitos da democracia, em que o governo é decidido pelo povo. Ato de tornar acessível a todas as pessoas e classes; popularização.
} 
Alguns dos benefícios advindos de tal experiência são: (i) comercialização direta de alimentos frescos, produzidos regionalmente (em um raio de $160 \mathrm{~km}$ ), caracterizando então uma modalidade de circuito curto de comercialização; (ii) respeito ao meio ambiente, dado o modelo agroecológico de produção e a adequação dos alimentos à sazonalidade das culturas; (iii) aumento da oferta e demanda desse tipo de alimento, tendo em vista a lista de espera de 15 pessoas que aguardam para adentrar no Projeto, bem como outros agricultores ligados à Rede Ecovida de Agroecologia, que demonstram interesse em fazer parte da iniciativa; (iv) diversificação e aquecimento do mercado local de alimentos orgânicos, de forma a incentivar e promover a competitividade econômica da agricultura familiar, propiciando uma maior e mais justa remuneração ao produtor, e (v) a popularização deste tipo de alimento dado o preço mais acessível e justo repassado ao consumidor, quando comparado aos preços praticados nos demais mercados locais de Florianópolis. Tais aspectos denotam claramente a criação de um novo mercado, formado e fomentado pela rede de atores, cidadãos, envolvidos na cadeia. As iniciativas se articulam formando uma rede de Células espalhadas por zonas/bairros da cidade, as quais se enquadram, então, na denominação de rede de cidadania agroalimentar, devido às características acima supracitadas.

Ainda, a experiência mostra-se como um exemplo empírico de construção social de mercados a partir de uma RAA, ao comprovar a criação de um modelo agroalimentar alternativo ao paradigma da industrialização contemporânea. Este não se dá apenas nas modificações das formas de consumo, mas também devido à contribuição que oferece à construção de um novo padrão de desenvolvimento, mostrando-se sustentável nas esferas social, ambiental, cultural, política e econômica, e fundado em bases territoriais. O modelo das CCR se revela um espaço de governança (decisão e suas interações) que combina elementos de proximidade geográfica e organizativa.

Nesse processo de articulação direta, princípios, como autonomia, solidariedade, segurança alimentar, justiça social, respeito à cultura, meio ambiente e tradição local, são notoriamente percebidos nas relações criadas entre produtores e consumidores, fato que pode ser constatado ao longo do processo de criação das Células e de replicação do modelo adotado.

\section{Conclusões}

Dada a centralidade do alimento para a vida e a sociedade humana, é notória a necessidade de rever o modelo econômico globalizado e construir uma realidade na qual a agricultura seja enfocada a partir de diretrizes que não estejam voltadas apenas para a reprodução do capital, mas ligada a uma matriz mais ecológica, humana e comunitária, de forma a aproximar quem produz de quem consome.

Verifica-se que a experiência das CCR se insere no escopo das abordagens que analisam o advento de redes de cidadania agroalimentar (RCA), que, para além da abordagem das redes agroalimentares alternativas (RAA), incorpora o componente da governança agroalimentar e a democratização do acesso a alimentos de qualidade superior. Verificam-se na iniciativa claros elementos de constituição de uma RCA na Grande Florianópolis, quando se integram em torno do abastecimento alimentar os agricultores e suas organizações, consumidores que se organizam, organizações sociais de apoio e instituições públicas. Tratase da geração de alternativas agroalimentares locais, construindo mercados a partir da mobilização de segmentos sociais interessados na transição para sistemas mais sustentáveis de produção, abastecimento e consumo de alimentos.

De acordo com os resultados alcançados até o momento, considera-se que a experiência poderá produzir impactos significativos em seu contexto territorial, assim como poderá contribuir para estudos futuros ligados ao desenvolvimento rural e urbano, e à constituição de RCA nas grandes cidades contemporâneas. O estudo dá ênfase à inserção de grupos de agricultores familiares e de consumidores no centro das discussões da cadeia agroalimentar, em um processo nitidamente transitório, que passa de uma experiência inicial ligada a uma iniciativa de RAA (na qual diferentes atores sociais aparecem focados em seus interesses de forma individualizada e menos articulada) para uma RCA, que incorpora elementos de governança cidadã e democratiza o acesso e a gestão do sistema agroalimentar, repensando 
as relações entre produtores e consumidores, bem como o abastecimento alimentar em um território populoso.

Conclui-se que as Células de Consumidores Responsáveis (CCR) são uma tecnologia social que tem potencial de expansão na cidade de Florianópolis-SC, associadas à ampla demanda por alimentos orgânicos, saudáveis e de origem conhecida. A promoção, ampliação e democratização do consumo de alimentos orgânicos/agroecológicos de origem local são necessidades das cidades populosas para superar as lacunas e promover o redesenho do sistema agroalimentar hegemônico.

Finalmente, pesquisas futuras podem se dedicar a responder às seguintes indagações: Quais os elementos-chave das redes de cidadania agroalimentar quanto à sua amplificação como modelo de abastecimento alimentar de cidades populosas?; Qual o papel e o potencial da educação para o consumo na ampliação de redes como a estudada?, e De que forma a sociedade civil organizada pode democratizar o sistema agroalimentar, a ponto de se tornar um agente determinante de políticas públicas que venham a suportar um modelo mais sustentável de desenvolvimento?

\section{Referências}

Anjos, F. S., \& Caldas, N. V. (2018). Uma resposta sólida a um regime agroalimentar em crise: o fenômeno GÁS na Itália. Revista Brasileira de Ciências Sociais, 32(95), 1-18.

Bauman, Z. (2008). Vida para consumo: a transformação das pessoas em mercadoria. Rio de Janeiro: Zahar.

Buainain, A. M. (2006). Agricultura familiar, agroecologia e desenvolvimento sustentável: questões para debate. Brasília, DF: IICA.

Bucak, T., \& Demir, D. (2014). The place and importance of Earth Markets within scope of Ecogastronomy: the example of Earth Market. International Journal of Applied Science and Technology, $4(2), 243-251$.

Cassarino, J. P., \& Damasceno, A. F. (2013). Agroecologia, construção social de marcados e a constituição de sistemas agroalimentares alternativos: uma leitura a partir da Rede Ecovida de Agroecologia. In P. A. Nierdele, L. Almeida \& F. M. Vezanni (Eds.), Agroecologia: práticas, mercados e políticas para uma nova agricultura. Curitiba: Kairós.

Dagnino, R. (2014). A tecnologia social e seus desafios. In Tecnologia Social: contribuições conceituais e metodológicas. Campina Grande: EDUEPB.

Darolt, M. R., Lamine, C., Brandenburg, A., Alencar, M. D. C. F., \& Abreu, L. S. (2016). Redes alimentares alternativas e novas relações produção-consumo na França e no Brasil. Ambiente \& Sociedade, 19(2), $1-22$.

Delgado, G. C. 1985. Capital financeiro e agricultura no Brasil: 1965-1985. São Paulo: Ícone/UNICAMP.

Facebook. (2019). Recuperado em 18 de fevereiro de 2019, de https://www.facebook.com/tvufsc/videos/2087819121248086/?fref=mentions

Gómez, C. R. P., Castillo, L. A. G., Correia, S. N., \& Oliveira, V. M. (2015). Turismo de Base Comunitária como Inovação Social: congruência entre os constructos. PASOS: Revista de Turismo y Patrimonio Cultural, 13(5), 1213-1227.

Goodman, D. (2003). The quality 'turn' and alternative food practices: reflections and agenda. Journal of Rural Studies, 19(1), 1-7.

Goodman, D. (2017). Espaço e lugar nas redes alimentares alternativas: conectando produção e consumo. In M. Gazzola \& S. Schneider (Eds.), Cadeias curtas e redes agroelimentares alternativas: negócios e mercados da agricultura familiar. Porto Alegre: Editora da UFRGS.

Goodman, M. K., \& Sage, C. (2014). Food transgressions: making sense of contemporary food politics (250 p.). Ashgate Publishing.

Grade, M., \& Mergen, C. (2018). Boletin de preços dos alimentos orgânicos no varejo de Florianópolis - SC. Florianópolis: UFSC.

Granovetter, M. S. (1985). Economic action and social structure: the problem of embeddedness. American Journal of Sociology, 91(3), 481-510.

Holanda, A. B. (2010). Míni dicionário Aurélio da Língua Portuguesa. 8. ed. Editora Positivo. 
Kneafsey, M., Venn, L., Schmutz, U., Balázs, B., Trenchard, L., Eyden-Wood, T., Bos, E., Sutton, G., \& Blackett, M. (2013). Short food supply chains and local food systems in the EU: a state of play of their socio-economic characteristics. Joint Research Centre Scientific and Policy Reports. Luxembourg: Publications Office of the European Union.

Lamine, C., Darolt, M., \& Brandenburg, A. (2012). The civic and social dimensions of food production and distribuction in alternative food networks in frace and southern Brazil. International Journal of Sociology of Agriculture and Food, 19(3), 383-401.

Marques, R. (2003). Os trilhos da nova sociologia econômica. In J. Marques \& R. Peixoto (Eds.). Oeiras, Portugal: Celta Editora.

Marsden, T., Banks, J., \& Bristow, G. (2000). Food supply chain approaches: exploring their role in rural development. Sociologia Ruralis, 40(4), 424-438.

Max-Neef, M. (2012). Desenvolvimento à escala humana. Blumenau: Edifurb.

Petrini, C. (2009). Slow food: princípios da nova gastronomia (245 p.). São Paulo: Editora Senac.

Ploeg, J. D. (2006). O modo de produção camponês revisitado. In S. Schneider (Eds.), A diversidade da agricultura familiar. Porto Alegre: UFRGS.

Polanyi, K. (2000). A grande transformação. 2. ed. Rio de Janeiro: Elsevier.

Renting, H., Marsden, T., \& Banks, J. (2003). Understanding alternative food networks: exploring the role of short food supply chain in rural development. Environment \& Planning, 35(3), 393-411.

Renting, H., Schermer, M., \& Rossi, A. (2012). Building food democracy: exploring Civic Food Networks and newly emerging forms of food citizenship. International Journal of Sociology of Agriculture and Food, 19(3), 289-307.

RIC Mais. (2019). Recuperado em 18 de fevereiro de 2019, de ricmais.com.br/sc/programas/balancogeral-florianopolis/projeto-da-ufsc-facilita-acesso-de-alimentos-organicos-com-precos-mais-baixos

Santos, B. S. (2003). Produzir para viver: os caminhos para a produção não capitalista. 2. ed. Porto Alegre: Afrontamento.

Santos, B. S. (2005). Semear outras soluções: os caminhos da biodiversidade e dos conhecimentos rivais. Rio de Janeiro: Civilização Brasileira

Schneider, S. (2010). Situando o desenvolvimento rural no Brasil: o contexto e as questões em debate. Revista de Economia Política, 30(3), 511-531.

Schneider, S., \& Gazolla, M. (2011). Os atores do desenvolvimento rural: perspectivas teóricas e práticas sociais. Porto Alegre: UFRGS.

Schneider, S., Marques, F. C., \& Conterato, M. (2016). In F. C. Marques, M. Conterato \& S. Schneider (Eds.), Construção de mercados e agricultura familiar: desafios para o desenvolvimento rural. Porto Alegre: UFRGS.

Silva, J. G. (2003). Tecnologia e agricultura familiar. 2. ed. Porto Alegre: Editora da UFRGS.

Steiner, P. (2006). A sociologia econômica. São Paulo: Atlas.

Tregear, A. (2011). Progressing knowledge in alternative and local food networks: critical reflections and a research agenda. Journal of Rural Studies, 27(4), 419-430.

YouTube. (2019). Recuperado em 18 de fevereiro de 2019, de https://www.youtube.com/watch?v=_3UI5xWYKN0\&t=1115s

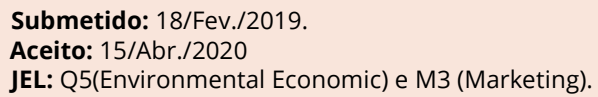

